\title{
Sürdürülebilirlik ve Finansal Performans Arasındaki İlișki: BİST Şirketleri Üzerine Bir Araştırma
}

\author{
Meltem GÜRÜNLÜ*
}

\section{ÖZET}

Son yillarda, çevresel, sosyal ve kurumsal yönetim ile ilgili konularda şirketlerin sürdürülebilirlik ilkelerine uyum çabaları bu alandaki çeşitli uluslararası insiyatiflerin önderliğinde ivme kazanmııs ve dünya borsalarında sosyal sorumlu yatırımları olan şirketlerden sürdürülebilirlik endeksleri oluşturulmaya başlanmıştır. Bu çalışmada, Borsa İstanbul'da sürdürülebilirlik endeksine dâhil olmanın uzun dönemli etkileri çeşitli panel veri tahmin yöntemleri ile analiz edilerek, sürdürülebilirlik endeksine dâhil olmak için yapılan çabaların şirketlerin itibarını arttırarak finansal başarıyı etkileyip etkilemediğinin araştırlması amaçlanmaktadır. Araştırma sonucunda, sürdürülebilirlik alanındaki yüksek performansla, finansal başarı arasında zayılf bir iliş̧i bulunmuştur. Bu zayıf ilişski, sürdürülebilirlik endeksine dâhil olmak için katlanılan çabaların yatırımcllar tarafindan yeterince değerlendirilmediği anlamına gelebilir.

Anahtar Kelimeler: Sürdürülebilirlik endeksi, finansal performans, panel veri.

JEL Sinıflandırması: G30, G32, G34, G35.

\section{TheRelationshipBetweenSustainabilityand Financial Performance: A ResearchStudy} on the Companies in the BIST

\section{ABSTRACT}

In recent years, efforts to adapt to the principles of sustainability in environmental, social and corporate governancematters have gained momentum under the leadership of various international initiatives in this field and sustainability indices have been started to be created by companies with socially responsible investments in the worlds to ckexchanges. In this study, the long-term effects of being included in the sustainability index in Borsa Istanbul are analyzed with various panel data estimation methods and it is aimed to investigate whether the efforts to be included in the sustainability index affect the financial success by increasing the company's reputations. As a result of the research, a weak relationship between high performance in the field of sustainability and financial success was found. This weaker relationship may mean that the endeavors to be included in the sustainability index are not rewarded enough by the investors.

Keywords: Sustainability index, financial performance, panel data.

Jel Classification: G30, G32, G34, G35.

Makale Gönderim Tarihi: 05.03.2019

Makale Kabul Tarihi: 06.08.2019

Makale Türü: Araştırma Makalesi

\footnotetext{
* Dr. Öğretim Üyesi, İstanbul Arel Üniversitesi, Uluslararası Ticaret ve Finans Bölümü, meltemgurunlu@arel.edu.tr, ORCHID No: 0000-0001-6790-4256
} 


\section{GİRiş}

Birleşmiş Milletler (BM) tarafindan 2006 yılında çevresel, sosyal ve kurumsal yönetim faktörlerini içeren sosyal sorumlu yatırımlar (SociallyResponsibleInvestments, SRI) konusundaki ilkelerin ilan edilmesinden sonra, sürdürülebilirlik kavramı ve şirket mali tablolarının sürdürülebilirlik ilkelerine uyumlu hale getirilme çabaları ivme kazanmıştır. Sürdürülebilirlik vurgusunun arttığı bu bağlamda, sosyal sorumlu yatırımları olan, globalraporlama, karbon saydamlı projesi ve sera gazı protokolü gibi şartlara uyan şirketlerden oluşan borsa endeksleri oluşturulmaya başlanmıştır. Borsalar, çevresel, sosyal ve kurumsal yönetim alanında yüksek sürdürülebilirlik standartlarına ulaşmak için, şirketleri sürdürülebilirlik performanslarını raporlayarak yatırımcıları bilgilendirmeye teşvik etmekte ve sürdürülebilirlik konularında daha katı listeleme kuralları geliştirmektedirler. Finansal bilgi kadar finansal olmayan bilgilerin de yatırımcılar için önem kazandığı ve cazip hale geldiği günümüz yatırım ortamında, sürdürülebilirlik sorunları, gelişmekte olan ülke piyasalarında da giderek önem kazanmaktadır (SustainableStockExchangesIniative, 2016).

Borsa İstanbul'da BIST sürdürülebilirlik endeksi, 4 Kasım 2014 tarihinden itibaren hesaplanıp yayınlanmaya başlanmıştır. BIST sürdürülebilirlik endeksinin temel amacı; borsada işlem gören ve sürdürülebilirlik performansları yüksek düzeyde olan şirketlerden ve sürdürülebilirlik ile ilgili anlayış ve uygulamaları arttıracak bir endeks oluşturmaktır. BIST sürdürülebilirlik endeksi, şirketlerin hem Türkiye hem de dünya için önem arz eden küresel ısınma, doğal kaynakların tükenmesi, su kaynaklarındaki azalma, sağlık, güvenlik ve istihdam ile ilgili konulara nasıl yaklaştığını ve bunlarla ilgili faaliyetlerin değerlendirmesini bağımsız bir gözle yerine getirmektedir. Buna ilaveten, endeks, şirketlere kurumsal sürdürülebilirlik performanslarını küresel ve yerel yaklaşımlarla karşılaştırma fırsatı vermekte, şeffaflık, hesap verebilirlik ve sürdürülebilirlikle ilgilirisk yönetimi becerileri için yeni hedeflerin belirlenmesi ve firsatların geliştirilmesi için bir performans değerlendirme aracıolmaktadır.

$\mathrm{Bu}$ çalışmada, sürdürülebilirlik endeksine dâhilolmanın, şirketlerin uzun dönemli finansal performansı üzerine etkisinin incelenmesi amaçlanmaktadır. Bu amaçla, 2014-2018 döneminde, Borsa İstanbul'da yer alan finansal sektör dişındaki 55 firmanın üçer aylık finansal rapor verilerine ait toplam 880 gözlemin içerildiği panel veri, havuzlanmış en küçük kareler, rassal (tesadüfi) etkiler ve sabit etkiler tahmin modelleri kullanılarak analiz edilmiştir.

\section{LITERATÜR TARAMASI}

Şirketlerin sürdürülebilirlik ile ilgili çevresel ve sosyal sorumluluk faaliyetlerinin finansal performans üzerindeki etkilerini anlatan farklı görüşler bulunmaktadır.(Lee ve Faff, 2009; Epstein,2018; EpsteinveRoy, 2003; HaighveHazelton, 2004). Bazı yazarlara göre (Herremans, AkathapornveMcInnes, 1993; Waddock ve Graves, 1997; Derwall, Guenster, BauerveKoedijk, 2005) şirketlerin sürdürülebilirlikle ilgili çevresel ve sosyal faaliyetleri veya sosyal sorumluyatırımlarının (SRI), bu şirketlere önemli ekonomik getirileri olmaktadır. Diğer yazarlara göre ise (Friedman, 1970; Aupperle, Carrol ve Hatfield,1985; Statman, 2006) karlı yatırımstratejilerinden, bu yüzden vazgeçilmesi, modern portföy teorisi ve finansal yönetimin temel amacı olan hissedar değerinin maksimize edilmesi ile çelişmektedir. $\mathrm{Bu}$ görüşe göre firmaların yaptığı sosyal sorumlu yatırımlar ile firmanın finansal performansı arasında bir bağlantı yoktur. Çünkü finansal piyasalar şirketlerin sosyal performanslarını fiyatlandıramamaktadır. 
Sürdürülebilirlik faaliyetleri ile ilgili kurumsalmaliyetlerinfinansal faydaya göredaha ağır bastığı durumlarda finansal performans üzerinde olumsuz etkiler gözlenmektedir. $\mathrm{Bu}$ durumda, yüksek bir kurumsal sürdürülebilirlik performansı, artan harcamalar nedeni ile azalan karlara, azalan firma değerine veya rekabetçi dezavantajlara yol açabilir (Telle, 2006; Friedman,1970). Bu tartışma kurumsal yönetim teorisi tarafindan da desteklenmektedir (Shleifer ve Vishny, 1997; Tirole, 2006). Kurumsal yönetim teorisine göreşirketlerde kurumsal yönetim yapıları optimum şekilde kurulduysa, yönetim, karlılığı en üst düzeye çıkarmanın yolunu zaten bulabilecektir. Kurumsal sosyal sorumluluk faaliyetleri ile ilgili harcamalar iseyönetime kendi çıkarları için kullanabileceklerive temsil maliyeti oluşturabilecekleri bir serbestlik alanı yaratmaktadır. Yöneticiler, bu konudaki yetkilerini kendi çıkarları doğrultusunda yanlış kullandıklarındafinansal verimsizlik riski artmaktadır. Özetleyecek olursak, kurumsal yönetim teorisi etrafında şekillenen bu görüşe göre sürdürülebilirlikle ilgili yatırımların hissedarların çıkarlarını maksimize etmeyen, maliyet etkinliği olmayan ve bu yüzden firma değerini azaltan bir gider çeşidi olduğu savunulmaktadır. Firmanın sürdürülebilirlikteki performansı, firmanın karlılığını ve rekabet avantajını azaltmaktadır.

Bunun tam tersine sürdürülebilirlik performansının finansal performans üzerindeki olumlu etkisine ilişkin argümanlarpaydaş teorisi etrafında şekillenmiştir. Paydaş teorisi, sürdürebilir sosyal sorumlu yatırımlarınüçüncü taraflara yüklenen dışsallaştırılmış maliyetlerin boyutunun azaltılmasındaki rolünü vurgulamaktadır. Friedman (1970), şirketlerin sosyal sorumluluk kavramına yaptığı eleştiride hükümetin mülkiyet haklarını tanımladığını, böylece dışsal maliyetlere yol açanbir etkinin olmayacağını varsayarken, Heal (2005), hükümetin dişsallık maliyetleri ile ilgili ilgili tüm sorunları tam olarak çözemediğini ve piyasaların yeterince rekabetçi ve etkin olmadığını savunmaktadır. $\mathrm{Bu}$ nedenle, şirketlerin yapacağı kurumsal, çevresel ve sosyal yatırımlar, toplumun üzerine yüklenen, dışsal maliyetleri azaltıcı etki yapabilir, eksik piyasa mekanizmalarının ve dolayısıyla eksik düzenlemelerin yerine geçebilir ve hükümet, genel kamu, sivil toplum kuruluşları, çalışanlar, müşteriler, rakipler gibi şirketler ve paydaş grupları arasındaki anlaşmazlıkları azaltabilir. $\mathrm{Bu}$ anlaşmazlıkların azaltılmasının, kurumsal karları ve dolayısıyla finansal performansı en azından uzun vadede arttırdığı söylenebilir. Paydaş teorisine göre firmanın paydaşlarının desteğini almak için çevresel ve sosyal faaliyetlere katılması ve bu alanda sosyal sorumlu yatırımlar (SRI) yapması faydalıdır. Bu, verimlilikte artışa yol açacaktır ve dolayısı ile sosyal sorumluluk amacı taşımayan diğer firmalara göre daha fazla rekabet edebilme gücü ve daha yüksek finansal performans anlamına gelmektedir (WaddockveGrave, 1997).

Özetleyecek olursak, sürdürülebilirlikle ilgili sosyal yatımlar, firma geniş bir paydaş grubunun desteğini alacağı için firmanın riski azalmakta ve bu uzun dönemde değer artışı olarak geri dönmektedir. Bu yüzden de sürdürülebilirlikle ilgili strateji geliştirmeyen firmaların uzun dönemde başarılı olamamaları mümkündür. Ayrıca, sürdürülebilirlik performansı ile finansal performans arasındaki ilişki, firmanın içinde bulunduğu ülkede hissedar haklarının savunulabileceği ve firmanın faaliyetlerinin şeffaf bir şekilde izlenebileceği gelişmiş bir hukuk sisteminin varlığ sahip ülkelerde, hissedarlar sürdürülebilirlikle ilgili yatırımları ve faaliyetleri değerli bulabilecekler ve fiyatlandırabileceklerdir. Dolayısı ile sürdürülebilirlik performansı ve finansal performans arasındaki ilişki de olumlu yönde olacaktır(Ararat, YurtogluveSüel 2014). 
Dünyada ekonomisinde finansal sürdürülebilirlik vurgusu giderek arttığından, çeşitli ülkelerdeki borsalarda sosyal sorumluyatırımları olan, global raporlama, karbon saydamlık projesi ve sera gazı protokolü gibi şartlara uyan şirketlerden oluşan sürdürülebilirlikle ilgili borsa endeksleri kurulmaya başlanmıştır. Çevresel, sosyal ve kurumsal yönetim alanında yüksek sürdürülebilirlik standartlarına ulaşmak için borsalar, şirketleri sürdürülebilirlik performanslarını raporlayarak yatırımcıları bilgilendirmeye etmeye teşvik etmekte ve sürdürülebilirlik konularında daha katı listeleme kuralları geliştirmektedirler (SustainableStockExchangesIniative, 2016).

İlk sürdürülebilirlik endeksi Mayıs 1990'da hesaplanmaya başlanan ve Kuzey Amerika şirketlerini kapsayan Domini 400 Sosyal Endeksi (DSI: Domini 400 Social Index)'dir. Sürdürülebilirlik endeksleri için dönüm noktalarından birisi ise Dow Jones Sürdürülebilirlik Endeksi (DJSI) serisinin 1999 yılı itibariyle başlamasıdır. DJIS Dünya, DJSI Kuzey Amerika, DSJI Avrupa, DSJI Asya-Pasifik gibi birçok endeks yer almaktadır. Bir diğer dönüm noktası ise 2001 yılı itibariyle başlayan FTSE4Good Endeks serisidir. Bunun içeresinde FTSE4Good ABD (ve ABD 50), FTSE4Good Avustralya 30, FTSE4Good Japonya, FTSE4Good Avrupa (ve Avrupa 50), FTSE4Good Birleşik Krallık (ve Birleşik Krallık 50), FTSE4Good IBEX gibi birçok endeks yer almaktadır. Gelişmekte olan ülkelerde ise SRI endeksleri 2004'ten itibaren oluşturulmaya başlanmış, bu bağlamda 2004 yılında Güney Afrika, 2005 yılında Brezilya, 2006 yılında Malezya ve ilerleyen yıllarda da Hindistan, Mısır, Çin, Kore gibi ülkeler için endeksler oluşturulmuştur. Türkiye için BIST sürdürülebilirlik endeksi ise 4 Kasım 2014 tarihi itibariyle hesaplanmaya başlamıştır (Gök ve Özdemir, 2017; Demirel ve Erdoğan, 2016).

Şirketlerin sürdürülebilirlik alanındaki performansı ile finansal performansı arasında bir ilişki olup olmadığı konusunda birçok ampirik çalışma yapılmıştır. Cunha ve Samanez (2013) Brezilya borsasındaki sürdürülebilirlik endeksi ile ilgili çalışmalarında, sürdürülebilirlik endeksindeki şirketlerin tarihsel performansını (2005-2010), piyasadaki diğer şirketlerin performansları ile karşılaştırmışlardır. Bulgular, sürdürülebilirlik endeksindeki hisse senetlerinin artan likidite ve düşük çeşitlendirme riski gibi özellikler gösterse de, finansal performanslarının sürdürülebilirlik endeksinde olmayan şirketlerle karşılaştırıldığında tatmin edici düzeylerde olmadığı yönündedir(Oberndorfer, Schmidt, Wagner ve Ziegler (2013). 1999-2002 yılları arasında Alman şirketlerin DJSI dünya ve DJSI Avrupa sürdürülebilirlik endekslerine dâhil olmalarının hisse senedi getirilerinde yarattığ değişiklikleri inceledikleri çalışmada, söz konusu şirket getirilerinde düşüş bulmuşlardır.

Gök ve Özdemir (2017), Borsa İstanbul sürdürülebilirlik endeksi performansının, BIST100 performansı ile karşılaştırıldığı çalışmada, 2014 ile 2016 arası dönem araştırılmıştır. Yazarların, riske ayarlı getiri analizi perspektifinden yaptıkları araştırmada, buldukları bulgular, yatırımcının kişisel değerleri bir kenara bırakıldığında, sürdürülebilirlik endeksi'nin yatırımcılar için finansal çıktı itibariyle finansal bir teşvik ediciye sahip olmadığına işaret etmektedir. Ancak, sürdürülebilirlik endeksi'nin yakın zamanlarda hesaplanmaya başlaması ve sosyal sorumlu yatırım yaklaşımının yeni olup, konuya dair farkındalığın artabilecek olması göz önünde bulundurulduğunda, yatırımcıların tepkilerinin zaman içerisinde farklılaşabileceği düşünülmektedir.

Lopez, Garcia ve Rodriguez (2007), 1998-2004 yılları arasında Dow Jonessürdürülebilirlik endeksiDJSI'ye üye olan firmalar ile sadece Dow Jones Global 
Endeksi'ne üye olan şirketlerin finansaltrendlerini karşılaştırılmıştır. İlk yıllarda yapılan sürdürülebilirlikle ilgilifaaliyetlerin firmaların performans göstergelerinenegatif etkisinin olduğu tespit edilmiştir. Sürdürülebilirlikle ilgili maliyetlerin finansal performans üzerine kısa dönemde olumsuz etkisi bulunmaktadır. Çalışmada, uzun dönemdeki etkinin de araştırılması gerektiğivurgulanmıştır. Lourenço, Callen, BrancoveCurto (2014), 2008-2010 döneminde Dow Jones endeksinde yer alan sürdürülebilirlik konusunda yüksek standartlara sahip firmalar ile yüksek standartlara sahip olmayan toplam 600 firmanın öz kaynaklarının ve net karının piyasa tarafından nasıl değerlendirildiğini kıyaslamıştır. Sonuçlar, firmaların dış itibar algısını etkilemek için sürdürülebilirlik konusundaki kararlılıklarını belirttikleri sinyal teorisi objektifinden yorumlanmaktadır. Bir firmanın sürdürülebilirliği sağlama konusundaki itibarı, firmanın beklenen nakit akışının değerini artırabilecek ve nakit akışlarının değişkenliğini azaltabilecek maddi olmayan bir değerdir. Bulgular, iyi sürdürülebilirlik şöhretine sahip firmaların net gelirlerinin piyasa tarafından fiyatlanmasının diğer firmalar göre daha yüksek değere sahip olduğunu göstermektedir.

Orsato, Mendes-da-Silva, Garcia, MonzoniveSimonetti(2015)2005-2011 y1llarında Brezilya'daki Sao Paulo Borsası'nda kurumsal sürdürülebilirlik endeksine dahil edilmenin firmalar açısındanilave finansal getiri yaratıp yaratmadığını geçmiş literatür, anketler ve ikincil veriler kullanılarak araştırmışlardır. Çalışma, sürdürülebilirlik endeksine dâhiledilmenin firmaların bilgiye erişim, yeni olanaklara erişim ve itibar kazanma gibi maddi olmayan değerini arttırdığınıve dolayısı ile şirketlerinsürdürülebilirlik endeksinde yer almak için harcadıkları çabaya değdiğini açıklamaktadır.

Özkan, Tanç ve Taşdemir (2018), sürdürülebilirlik raporları kapsamında işletmelerin kurumsal sosyal sorumluluk açıklamalarının finansal performansları üzerinde etkisi olup olmadığını tespit etmeyi amaçladıkları çalışmalarında BİST sürdürülebilirlik endeksinde yer alan 35 işletme ile ilgili bir araştırma yapmışlardır. Araştırma bulgularına göre işletmelerin kurumsal sosyal sorumluluk açıklamalarının kârlılık oranları üzerine pozitif etkiye sahip olduğu tespit edilmiştir.

Curran ve Morran (2007), finansal performansın, sürdürülebilirlikte gösterilen performansının şirkete sağladığı itibardan etkilenip etkilenmediğini araştırmaktadır. Olay çalışması yönteminin kullanıldığı çalışmada, sürdürülebilirlikle ilgili olumlu veya olumsuz duyurular ile hisse senedi fiyat performansı arasındaki ilişki incelenmiştir. FTS4Good İngiltere sürdürülebilirlik endeksine dâhil edilme veya endeksten silinmenin hisse senedi fiyatlarına etkisi incelenmiştir. Sonuçlar FTS4Good sürdürülebilirlik endeksine dâhil edilmenin veya silinmenin günlük getirileri beklenilen şekilde etkilediğini fakat istatistiki olarak önemli ve anlamlı bir fark yaratmadığını göstermektedir.

\section{ARAŞTIRMA METODOLOJISI}

Sürdürülebilirlik endeksinde yer almanın firmaların finansal performansı üzerine etkilerini araştıran çalışmalar genellikle, kısa dönemli olarak hisse senedi getirilerinin piyasaperformansına odaklanan olay çalışması üzerine yoğunlaşmıştır. Fakatsürdürülebilirlik endeksine dâhil olmanın, firmanın muhasebe temellifaaliyet performansı (örneğin; firma varlıklarının getiri oranı) ve firma değeri(örneğin; Tobin'in Q rasyosu) üzerinde uzun dönemli etkilerinin olması da muhtemeldir ve araştırılmalıdır. Bu çalışmada, Elsayed ve Paton (2005), Telle (2006), Bechetti, Giacamo ve Pinnacchio(2008) ve Wagner (2010)gibi yazarların 
yaptığ çalışmalara paralel olarak sürdürülebilirlik endeksinin finansal performans üzerindeki uzun dönemli etkilerini incelemek içinpanel veri analizi ile ilgili çeşitli tahmin yöntemlerine başvurulmuştur.

Bu kapsamda, çalı̧̧mada 2014-2018 y1lları arasında Borsa İstanbul'da yer alan finansal sektör dışındaki 55 firmanın üçer aylık finansalrapor verilerini kapsayan toplamda 880gözlemin yer aldığı dengeli bir panel veri seti analiz edilmiştir.Bu şirketlerin 25 tanesi 2014-2018 dönemde BISTsürdürülebilirlik endeksinde yer almaktadır.

Buna göre çalışmada kullanılan genelleştirilmiş model aşağıda yer almaktadır.

$$
\mathrm{FP}_{\mathrm{i}, t+1}=\beta_{0}+\beta_{1} \mathrm{SE}_{\mathrm{it}}+\beta_{2} \mathrm{BYK}_{\mathrm{it}}+\beta_{3} \mathrm{BRC}_{\mathrm{it}}+\beta_{4} \mathrm{BYM}_{\mathrm{it}}+\beta_{5} \mathrm{SY}_{\mathrm{it}}+\alpha_{\mathrm{i}}+\alpha_{\mathrm{t}}+\varepsilon_{\mathrm{it}}
$$

$\mathrm{FP}_{i, t+1}$ Firma performansı ile ilgili değiş̧kenleri, $\mathrm{SE}_{\mathrm{it}}$ sürdürülebilirlik endeksine dâhil olma ile ilgili kukla değiş̧eni, $B Y K_{\text {it }}$ firma büyüklüğünü, $\mathrm{BRC}_{\text {it }}$ toplam borcun toplam varlıklara oranını, $\mathrm{BYM}_{\mathrm{it}}$ net satı̧̧lardaki büyüme oranını, $\mathrm{SY}_{\mathrm{it}}$ sermaye yoğunluğu oranını ifade eden değişkenlerdir. $\alpha_{i}$ firmaya özgü etkileri, $\alpha_{t}$ ise zamana özgü etkileri belirtmekte kullanılmaktadır. Bağımlı değişken ve bağımsız değişkenler arasındaki nedensellik ilişkisinin yönünü daha sağlıklı bir şekilde ortaya koyabilmek için bağımsız değişkenlerin gecikmeli değerleri kullanılmaktadır.Modelde kullanılan tüm değişkenlerle ilgili tanımlara ve açıklamalara aşağıda yer verilmektedir.

\section{Firmanın performansı ile ilgili bağımlı değişkenler (FP)}

Firmanın performansını ölçmek için iki ana değişken kullanılmıştır. Bunlardan birincisi Faaliyet karının toplam varlıklara olan oranını ölçen varlık getiri oranıdır (VGO). Faaliyet karını ölçmek için vergi ve faiz harcamaları öncesi elde edilen kar kullanılmıştır (Waddock ve Graves, 1997). Kullanılan ikinci bağımlı değişken ise Tobin'in Q rasyosudur. $\mathrm{Bu}$ rasyo kısaca, firma piyasa değerinin, firma varlıklarının yerine koyma maliyetine oranı olarak tanımlanabilir (Tobin, 1969). Tobin'in Q rasyosu daha sonra Lindenberg ve Ross (1981) ve Chung ve Pruitt (1994) tarafından daha da geliştirilmiştir. Daha detaylı olarak, bu rasyo, adi hisse senetlerinin piyasadeğerinin, tercihli hisse senetlerinin, uzun dönemli borcun ve kısa dönemli borcun defter değerleri ile toplanarak toplam varlıkların defter değerine oranlanması yolu ile bulunmaktadır. Tobin q oranının 1'den büyük olması, firmanın kıt kaynakları etkin kullandığının bir göstergesi olarak yorumlanmaktadır. Öte yandan bu oranın 1'in altında olması, kaynaklardan etkin bir biçimde yararlanılamadığını göstermektedir (Canbaş, Doğukanlı ve Düzakın, 2004). Varlıkların getiri oranı (VGO)'ya göre Tobin'in Q rasyosu daha ileriye dönük bir değişkendir ve yatırımcıların yatırım kararı hakkındaki algilamalarını daha kolay ortaya koymaktadır.

\section{Bağımsız Değişkenler}

\section{Sürdürülebilirlik Endeksine Dâhil Olma ile İlgili Kukla Değişken (SE)}

Firma, BİST sürdürülebilirlik endeksine dâhil ise kukla değişken 1 , değil ise 0 değerini almaktadır. 


\section{Firmanın Toplam Varlıklarının Büyüklüğü (BYK)}

Firmanın büyüklügü toplam varlıkların doğal logaritması olarak ifade edilmektedir ve doğrusal olmayan etkilerin de incelenmesi sağlanmaktadır.

\section{Toplam Borcun Toplam Varlıklara Oranı (BRC)} vermektedir.

$\mathrm{Bu}$ değişken firma sermaye yapısı ve yönetimin maruz kaldığı firma riskiile ilgili bilgi

\section{Net Satışlardaki Büyüme Oranı (BYM)}

Net satışların bir önceki yıla göre yüzde kaç büyüdüğünü göstermektedir ve firmanın büyüme dinamiklerinin ortaya konulmasında kullanılmaktadır.

\section{Sermaye Yoğunluğu Oranı (SY)}

Sermaye yoğunluğu oranı, sermaye harcamalarının net satışlara oranı olarak hesaplanmaktadır Firmanın üretim sürecinde kullanılan teknolojinin yoğunluğu gösteren bu oran, firmanın uzun dönemli büyüme olanakları ile ilgili bilgi vermektedir.

Yukarıdaki değişkenleri içeren özet istatistikler ve korelasyon matrisi aşağıdaki tablolarda sunulmaktadır.

Tablo 1. Özet İstatistikler

\begin{tabular}{|l|l|l|l|l|}
\hline Değişkenler & Ortalama & Standart Sapma & Minimum & Maksimum \\
\hline VGO & 7.55 & 6.35 & -18.17 & 65.18 \\
\hline Tobin Q & 1.40 & 1.35 & 0.02 & 16.45 \\
\hline BYK & 25.53 & 1.84 & 17.55 & 28.59 \\
\hline BRC & 0.252 & 0.152 & 0 & 1.46 \\
\hline BYM & 0.16 & 0.45 & -0.65 & 11.69 \\
\hline SY & 0.10 & 0.18 & 0 & 5.25 \\
\hline
\end{tabular}

Tablo 2. Korelasyon Matrisi

\begin{tabular}{|l|l|l|l|l|l|l|l|}
\hline & ROA & Tobin Q & SE & BYK & BRC & BYM & SY \\
\hline VGO & 1 & & & & & & \\
\hline Tobin Q & 0.64 & 1 & & & & & \\
\hline SE & -0.04 & -0.07 & 1 & & & & \\
\hline BYK & -0.53 & -0.42 & 0.23 & 1 & & & \\
\hline BRC & -0.06 & -0.09 & 0.02 & 0.14 & 1 & & \\
\hline BYM & 0.05 & 0.08 & -0.11 & -0.02 & 0.01 & 1 & \\
\hline SY & -0.06 & -0.05 & -0.03 & -0.08 & 0.09 & 0.02 & 1 \\
\hline
\end{tabular}




\section{AMPIRIKK ANALİZ VE BULGULAR}

Borsa İstanbul'da işlem gören 55 şirketin üçer aylık dönemler itibarı ile 2014-2018 yılları arasında incelendiği ve toplamda 880 gözlemin yer aldığı panel veri,havuzlanmış en küçük kareler, rassal etkiler ve sabit etkiler için tahmin yöntemlerine göre incelenmiştir. Bağımsız değişkenlerin finansal performans ile ilgili bağımlı değişkenler olan varlık getiri oranları (VGO) ve Tobin'in Q rasyosu üzerinde etkileri Tablo 3 ve Tablo 4'de ayrı ayrı gösterilmektedir. Bütün bağımsız değişkenlerin 1 yıl gecikmeli değerleri kullanılmıştır. Havuzlanmış en küçük kareler yöntemi (EKK) ve sabit etkiler yönteminde modelin genel olarak geçerliliğini sınayan $F$ testi ve rassal etkiler yönteminde modelin tutarlılığını sınayan Wald testi sonuçları istatistiki olarak anlamlı çıkmıştır.

Havuzlanmış en küçük kareler yöntemine göre, sürdürülebilirlik endeksine dâhil olmanın, varlık getiri oranları(VGO) ve Tobin'in Q rasyosu üzerinde sırası ile \%1 ve \%5 seviyelerinde anlamlı ve olumlu bir etkisi vardır. Sermaye yoğunluğu ve firma büyüklüğü değişkenlerinin her iki bağımlı değişken üzerindeki etkisi negatiftir ve \%1 seviyesinde anlamlıdır. Net satışlardaki büyüme oranının Tobin'inQ rasyosu üzerinde pozitif ve $\% 5$ düzeyinde anlamlı bir etkisi bulunmaktadır. Ancak, bu modelde gözlemlenemeyen bireysel etkiler nedeni ile yanlılıklar bulunmaktadır.

Gözlemlenemeyen bireysel etkiler sorununu ortadan kaldırmak için daha esnek varsayımlara sahip panel veri modelleri ile de çalışılmıştır. Rassal etkiler ve sabit etkiler modellerinde sermaye yoğunluğu (SY) ve varlık getiri oranları (VGO) arasındaki negatif ilişki istatistiki olarak geçerli olmamaktadır. Aynı şekilde, sermaye yoğunluğu (SY) ve Tobin'in Q rasyosu arasındaki ilişki rassal ve sabit etkiler modellerindeanlamsız olmaktadır. Hausman testinin sonuçlarına göre varlık getiri oranlarının açıklanmasında sabit etkiler modelinin kullanılması, rassal etkiler modeline göre üstünlük sağlayacaktır. Tobin'in $Q$ rasyosu ise rassal etkiler modeli ile daha iyi açıklanabilmektedir. Fakat ana açıklayıcı değişken sürdürülebilirlik endeksine dâhil olmanın (SE) Tobin'in Q rasyosu üzerindeki etkisi rassal ve sabit etkili modellerde istatistiki olarak anlamsız olmaktadır.Sürdürülebilirlik endeksine dâhil olmanın varlık getiri oranları (VGO) üzerindeki pozitif etkisi sabit etkili ve rassal etkilipanel veri modellerinde ise $\% 90$ güven aralığında istatistiki olarak anlamlı olmaktadır.

Tablo 3. Sürdürülebilirlik Endeksine Dâhil Olmanın Varlık Getiri Oranına (VGO) Etkileri

\begin{tabular}{|l|l|l|l|}
\hline $\begin{array}{l}\text { Açıklayıc1 } \\
\text { Değişkenler }\end{array}$ & $\begin{array}{l}\text { HavuzlanmışEKK } \\
\text { Modeli }\end{array}$ & Rassal Etkiler Modeli & Sabit Etkiler Modeli \\
\hline SE & $1.12^{* * *}$ & $0.56^{*}$ & \\
\hline BYK & $(0.0012)$ & $(0.06)$ & $0.54^{*}$ \\
& $-2.11^{* * *}$ & $-1.70^{* * *}$ & $(0.03)$ \\
\hline BRC & $(0.001)$ & $(0.003)$ & -0.64 \\
& 1.23 & $6.34^{* * *}$ & $(0.151)$ \\
\hline BYM & $(0.142)$ & $(0.0051)$ & $9.57^{* * *}$ \\
\hline
\end{tabular}




\begin{tabular}{|l|l|l|l|}
\hline & $(0.13)$ & $(0.121)$ & $(0.134)$ \\
\hline SY & $-2.15 * * *$ & -0.74 \\
$(0.0011)$ & $(0.22)$ & -0.18 \\
& $40.95 * * *$ & - & $12.35 * * *$ \\
\hline F testi & - & $286.92 * * *$ & - \\
\hline Wald istatistiği & 0.45 & 0.43 & 0.09 \\
\hline $\mathrm{R}^{2}$ & - & $21.45 * * *$ & $21.45 * * *$ \\
\hline Hausman istatistiği & - & $815.11^{* * *}$ & - \\
\hline Breusch -pagan & - & 880 & 880 \\
\hline $\mathrm{N}$ & 880 & & \\
\hline
\end{tabular}

$* * * \% 1, * * \% 5, * \% 10$ istatistiksel anlam seviyeleri

Tablo 4. Sürdürülebilirlik Endeksine Dâhil Olmanın Tobin Q Rasyosuna Etkileri

\begin{tabular}{|l|l|l|l|}
\hline $\begin{array}{l}\text { Açıklayıc1 } \\
\text { Değişkenler }\end{array}$ & $\begin{array}{l}\text { Havuzlanmış Regresyon } \\
\text { Modeli }\end{array}$ & Rassal Etkiler Modeli & Sabit Etkiler Modeli \\
\hline SE & $\begin{array}{l}0.14 * * \\
(0.032)\end{array}$ & $\begin{array}{l}0.05 \\
(0.156)\end{array}$ & $\begin{array}{l}-0.00 \\
(0.34)\end{array}$ \\
\hline BYK & $-0.35^{* * *}$ & $-0.33 * * *$ \\
& $(0.0027)$ & $(0.0058)$ & $-0.45^{* * *}$ \\
\hline BRC & $0.43^{*}$ & 0.22 & $(0.0047)$ \\
\hline BYM & $(0.09)$ & $(0.35)$ & 0.09 \\
& $0.21 * *$ & 0.06 & $(0.321)$ \\
\hline SY & $(0.0482)$ & $(0.253)$ & 0.05 \\
& $-0.32^{* * *}$ & -0.14 & $(0.361)$ \\
\hline R & $(0.001)$ & $(0.283)$ & -0.05 \\
\hline F testi & & & $(0.351)$ \\
\hline Wald istatistiği & - & - & 880 \\
\hline${ }^{2}$ & $17.24 * * *$ & $305.66 * * *$ & $14.82^{* * *}$ \\
\hline
\end{tabular}

$* * * \% 1, * * \% 5, * \% 10$ istatistiksel anlam seviyeleri

\section{SONUÇ}

$\mathrm{Bu}$ çalışmada, borsada sürdürülebilirlik endeksine dahil olmanın, şirketlerin finansal performans1 üzerinde uzun dönemde nasıl bir etkiye sahip olduğu ampirik olarak incelenmiştir. $\mathrm{Bu}$ bağlamda, Borsa İstanbul'da işlem gören finansal sektör dişındaki 55 şirketin 2014-2108 yılları arasındaki üçer aylık finansal rapor verileri dikkate alınarak 880 firma-zaman verisinden oluşan bir panel veri seti ile çalışılmıştır. Bu şirketlerden 25 tanesi 
sürdürülebilirlik kriterlerini yerine getirdiği bağımsız bir derecelendirme kuruluşu (EIRIS) tarafından teyit edilerek BİST sürdürülebilirlik endeksinde yer almaktadır. Havuzlanmış en küçük kareler, rassal etkiler ve sabit etkiler modelleri test edilerek, sürdürülebilirlik endeksine dâhil olmanın, varlık getiri oranları (VGO) ve Tobin'in Q rasyosu üzerindeki etkileri analiz edilmiştir. Sürdürülebilirlik endeksine dâhil olmanın finansal raporlama ve muhasebe temelli varlık getiri oranları (VGO) üzerinde pozitif ancak sınırlı bir etkisi vardır. Sürdürülebilirlik endeksine dâhil olan şirketler zaten borsanın en büyük ve lider şirketlerinden oluşmaktadır. Sürdürülebilirlik endeksine dâhil olmanın, piyasa temelli ve sürdürülebilirlik ile ilgili yatırımc1 algısını ortaya koyan Tobin'in $Q$ değeri üzerinde ise anlamlı bir etkisibulunamamıştır. Bu zayıf ilişki, sürdürülebilirlik endeksine dâhil olmakiçin katlanılan çabaların yatırımcılar tarafından yeterince değerlendirilmediği anlamına gelebilir. Bu zayıf ilişkiden hareketle, bireysel yatırımcıların çevre, sosyal ve kurumsal yönetimle ilgili uzun dönemli düşünmediği ve konu ile ilgili farkındalıklarının yeterli olmadığı; daha uzun dönemli düşünebilen ve sürdürülebilirlikile ilgili daha bilinçli olan kurumsal yatırımcıların ise yeterli düzeyde kaynak ayırmadıkları söylenebilir. Ayrıca, sürdürülebilirlik performansı ve finansal performans arasındaki ilişkinin, hissedar haklarını koruma düzeyinin yüksek olduğu ve firmanın faaliyetlerinin şeffaf bir şekilde izlenebildiği gelişmiş bir hukuk sisteminin varlığı ile de ilgili olduğu söylenebilir. Gelişmiş hukuk sistemine sahip ülkelerde, hissedarlar sürdürülebilirlikle ilgili yatırımları ve faaliyetleri değerli bulabilecekler ve fiyatlandırabileceklerdir. Dolayısı ile sürdürülebilirlik performansı ve finansal performans arasındaki ilişsi de olumlu yönde olacaktır.

\section{KAYNAKLAR}

Ararat, M.-Suel, E. - Yurtoglu, B. B. (2014), "Sustainableİnvestment in Turkey: The Case in Context - An Update”, Sabanc1 University, http://dx.doi.org/10.2139/ssrn.2447937

Aupperle, K.E. - Carroll, A.B. -Hatfield,J.D (1985), “An EmpiricalExamination Of TheRelationshipBetweenCorporateSocialResponsibilityAndProfitability", Academy of Management Journal 28 (2), pp: 446-463. https://doi.org/10.5465/256210

Bechetti, L. - Giacamo, S. - Pinnachio, D. (2008), "Corporate Social Responsibility And Corporate Performance: EvidenceFrom A Panel Of US ListedCompanies", Journal of AppliedEconomics, 40(5), pp:541-567. https://doi.org/10.1080/00036840500428112

Canbaş, S. - Doğukanlı, H. - Düzakın, H. (2004),“Tobin Q Oranı Ve Günümüzde İşletme Kararları Açısından Önemi”,Çukurova Üniversitesi Sosyal Bilimler Enstitüsü Dergisi, 13 (2), pp: 57-74.

Chung, K.H. - Pruitt, S.W. (1994), “A Simple Approximation Of Tobin's Q”,Financial Management Journal, 23(3), pp:70-74.

Cunha, F. - Samanez, C.P. (2013), "PerformanceAnalysis Of SustainableInvestmentsInTheBrazilianStock Market: A StudyAboutTheCorporateSustainability Index (ISE)", JournalOf Ethics, 117, pp:1936, doi: $10.1007 / \mathrm{s} 10551-012-1484-2$ 
Curran, M. - Moran D. (2007), "ImpactOf TheFTSE4Good Index On FirmPrice: An EventStudy",Journal of Environmental Management, 82(4), pp:529-537.Doi: 10.1016/j.jenvman.2006.02.010

Demirel, B. - Erdoğan, M. (2016), "CorporateSustainabilityReportingInTheBIST Sustainability Index",International Journal of Business andSocialResearch, 6(10), pp:21-31.

http://dx.doi.org/10.18533/ijbsr.v6i10.999

Derwall, J. - Guenster, N. - Bauer,R. - Koedijk, K.C. (2005), “SociallyResponsibleInvesting: TheEco-efficiency Premium Puzzle", Financial AnalystsJournal, 61(2), pp: 5163.Doi:10.2469/faj.v61.n2.2716

Elsayed, K. - Paton, D. (2005), “TheImpact Of EnvironmentalPerformance On FirmPerformance:StaticAndDynamic Panel Data Evidence",StructuralChangeandEconomic Dynamics, 16, pp:395-412. http://dx.doi.org/10.1016/j.strueco.2004.04.004

Epstein, M.J. (2018), MakingSustainabilityWork: Best Practices in ManagingandMeasuringCorporateSocial, EnvironmentalandEconomicImpacts, Routledgepublications, Londonhttps://doi.org/10.4324/9781351280129

Epstein, M.J. - Roy, M. (2003), "MakingThe Business Case ForSustainability: LinkingSocialAndEnvironmentalActionsTo Financial Performance", TheJournal of CorporateCitizenship, 9, pp:79-96

Friedman, M. (1970), “The Social Responsibility Of Business Is To IncreaseItsProfits”, The New York Times Magazine, pp:122-126.

Gök, İ.Y. - Özdemir, O. (2017), “Borsa İstanbul Sürdürülebilirlik Endeksinin Performans Karakteristiği”, $\quad$ Sosyoekonomi, 25(34), pp:87105.Doi:10.17233/sosyoekonomi.290838

Hayward, L. (2018), "DoesTheStock Market Valueİnclusion On A Sustainability Index? An EventStudy Using TheDow JonesSustainabilityNorth America", College of Holly Cross, Master Thesis,https://crossworks.holycross.edu/econ_stu_scholarship/3, (Erişim Tarihi: 12.04.2019)

Haigh,M. - Hazelton, J. (2004), “Financial Markets: A ToolForSocialResponsibility?”,Journal of Business Ethics, 52(1), pp: 71.https://doi.org/10.1023/B:BUSI.0000033107.22587.0b

Heal, G. (2005), “CorporateSocialResponsibility: An EconomicAndfinancial Framework",TheGenevaPapers on Risk andInsurance -IssuesandPractice, 30(3), pp:387-409, https://doi.org/10.1057/palgrave.gpp.2510037

Herremans,I.M. - Akathaporn, P. - McInnes, M. (1993), "An Investigation Of CorporateSocialResponsibilityReputationAndEconomicPerformance", Accounting, 
OrganizationsandSociety, $\quad 18(7-8), \quad$ pp:587-604, https://doi.org/10.1016/03613682(93)90044-7

Lee, D. - Faff, R.W. (2009), "CorporateSustainabilityPerformanceAndIdiosyncratic Risk: A Global Perspective",The Financial Review, 44, pp:213-237. https://doi.org/10.1111/j.1540-6288.2009.00216.x

Lindenberg, E.B. - Ross, S.A. (1981), “Tobin's Q RatioAndIndustrialOrganization”,Journal of Business, 54(1), pp:1-32.

Lopez, M.V - Garcia, A. - Rodriguez, L. (2007), "Sustainable Development AndCorporatePerformance: A StudyBased On TheDow JonesSustainability Index",Journal of Business Ethics,75(3), pp: 285-300.https://doi.org/10.1007/s10551006-9253-8

Lourenço, I.C. - Callen, J.L. - Branco, M.C. - Curto, J.C. (2014), “TheValue Relevance Of ReputationForSustainabilityLeadership",Journal of Business Ethics, 119 (1), pp:17-28, Doi: 10.1007/s10551-012-1617-7

Oberndorfer, U. - Schmidt, P. - Wagner, M. - Ziegler, A. (2013), "DoesTheStock Market Value TheInclusionIn A SustainabilityStock Index? An EventStudy Analysis ForGermanFirms", Journal of EnvironmentalEconomicsand Management, 66(3), pp:497-509https://doi.org/10.1016/j.jeem.2013.04.005

Orsato,R. - Mendes-Da-Silva, W. - Garcia, A. - Monzoni, M. - Simonetti, R. (2015),"SustainabilityIndexes: WhyJoinIn? A Study Of TheCorporateSustainability Index (ISE) InBrazil", Journal of CleanerProduction, 96(1),pp: 161-170. https://doi.org/10.1016/j.jclepro.2014.10.071

Özkan, A. - Tanç, Ş.G. - Taşdemir, B. (2018), "SürdürülebilirlikAçıklamaları Kapsamında Sosyal Sorumluluğun Karlılık Üzerine Etkisi: BİST Sürdürülebilirlik Endeksinde Bir Araşıırma”, Muhasebe Bilim Dünyası Dergisi, 20(3), ss:560577.https://doi.org/10.31460/mbdd.390388

Shleifer, A. - Vishny, R.W. (1997), “ASurvey Of CorporateGovernance”,Journalof Finance 52(2), pp:737-783. https://doi.org/10.1111/j.1540-6261.1997.tb04820.x

Statman, M. (2006), "SociallyResponsibleIndexes: Composition, PerformanceAndTrackingErrors",Journal of Portfolio Management, 32(3), pp: 100110.

Sustainable Stock Exchanges Iniative (2016), "Report On Progress: A PaperPreparedForTheSustainableStockExchanges Global Dialague",https://unctad.org/en/PublicationsLibrary/unctad_sse_2016d1.pdf(Erişim Tarihi: 02.12.2018)

Telle, K. (2006), "ItPaysTo Be Green" - A PrematureConclusion?", Environmentaland Resource Economics, 35(3), pp:195-220 https://doi.org/10.1007/s10640-006-9013-3 
Tirole, J. (2006). TheTheory Of Corporate Finance, Princeton UniversityPress, NewYork

Tobin, J. (1969), “A General EqulibriumApproachToMonetaryTheory”, Journal of Money, CreditandBanking, 1(1), pp:15-29.

Waddock, S.A. - Graves, S.B. (1997), "The CorporateSocialPerformance-Financial Performance Link”, Strategic Management Journal, 18 (4), pp:303-319.

Wagner,

M. (2010),

"TheRole

Of

CorporateSustainabilityPerformanceForEconomicPerformance: A Firm-Level Analysis Of ModerationEffects". EcologicalEconomics, 69(7), pp:15531560.https://doi.org/10.1016/j.ecolecon.2010.02.017 
